\title{
Parity increases insulin requirements in pregnant women with type 1 diabetes
}

\section{Skajaa Gitte O', Fuglsang Jens', Kampmann Ulla ${ }^{2}$ and Ovesen Per $\mathbf{G}^{1}$}

'Department of Obstetrics and Gynecology, Aarhus University Hospital, Aarhus, Denmark,

2Department of Endocrinology and Internal Medicine, Aarhus University Hospital, Aarhus, Denmark.

\section{AIM}

The aim of the current study was to evaluate the insulin requirements in women with type 1 diabetes during pregnancy and to test whether parity affects insulin requirements.

\section{METHODS}

We conducted an observational cohort study consisting of women with type 1 diabetes who gave birth at Aarhus University Hospital from 2004-2014. Daily insulin requirements and HbAlc were collected from every visit during pregnancy.

\section{RESULTS}

Table 1: Demographics of type 1 diabetes patients included in the study

\begin{tabular}{|c|c|c|c|c|c|c|}
\hline Participants & $\mathbf{n}$ & 380 & & & & \\
\hline Births & $\mathbf{n}$ & 536 & & & & \\
\hline \multirow{2}{*}{ Repeaters } & \multirow[t]{2}{*}{$\mathbf{n}$} & \multicolumn{4}{|c|}{236 once, 132 twice, 12 thrice } & \\
\hline & & P1 & P2 & P3 & P3+4 & All \\
\hline Parity & $\mathbf{n}$ & 229 & 216 & 75 & 16 & 536 \\
\hline Parity & $\%$ & $43 \%$ & $40 \%$ & $14 \%$ & $3 \%$ & $100 \%$ \\
\hline Age & $\mathbf{y}$ & 29.1 & 32.0 & 33.6 & 36.7 & 31.1 \\
\hline BMI & $\#$ & 25.2 & 24.9 & 24.7 & 26.9 & 25.1 \\
\hline HbA1c ${ }^{a}$ & $\%$ & $7.6 \%$ & $7.5 \%$ & $7.8 \%$ & $8.1 \%$ & $7.6 \%$ \\
\hline$H b A 1 c$ & $\mathrm{mmol} / \mathrm{L}$ & 59.7 & 58.6 & 62.0 & 65.0 & 59.8 \\
\hline Duration ${ }^{b}$ & $\mathbf{y}$ & 14.4 & 15.6 & 16.7 & 12.8 & 15.2 \\
\hline
\end{tabular}

Figure 1: Mean daily insulin requirements in \% relative to prepregnancy levels

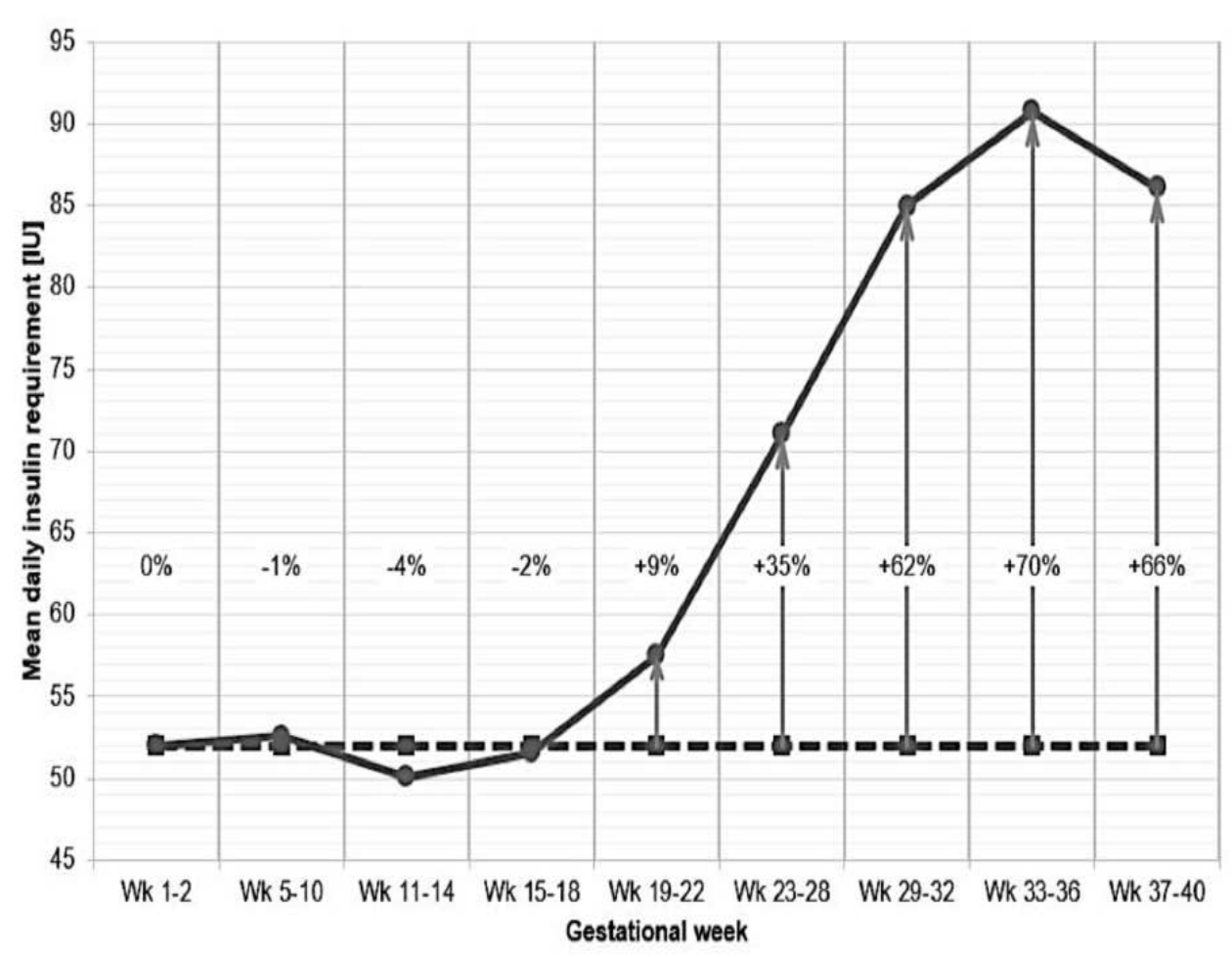

Figure 2: Difference in mean daily insulin requirement between parity groups

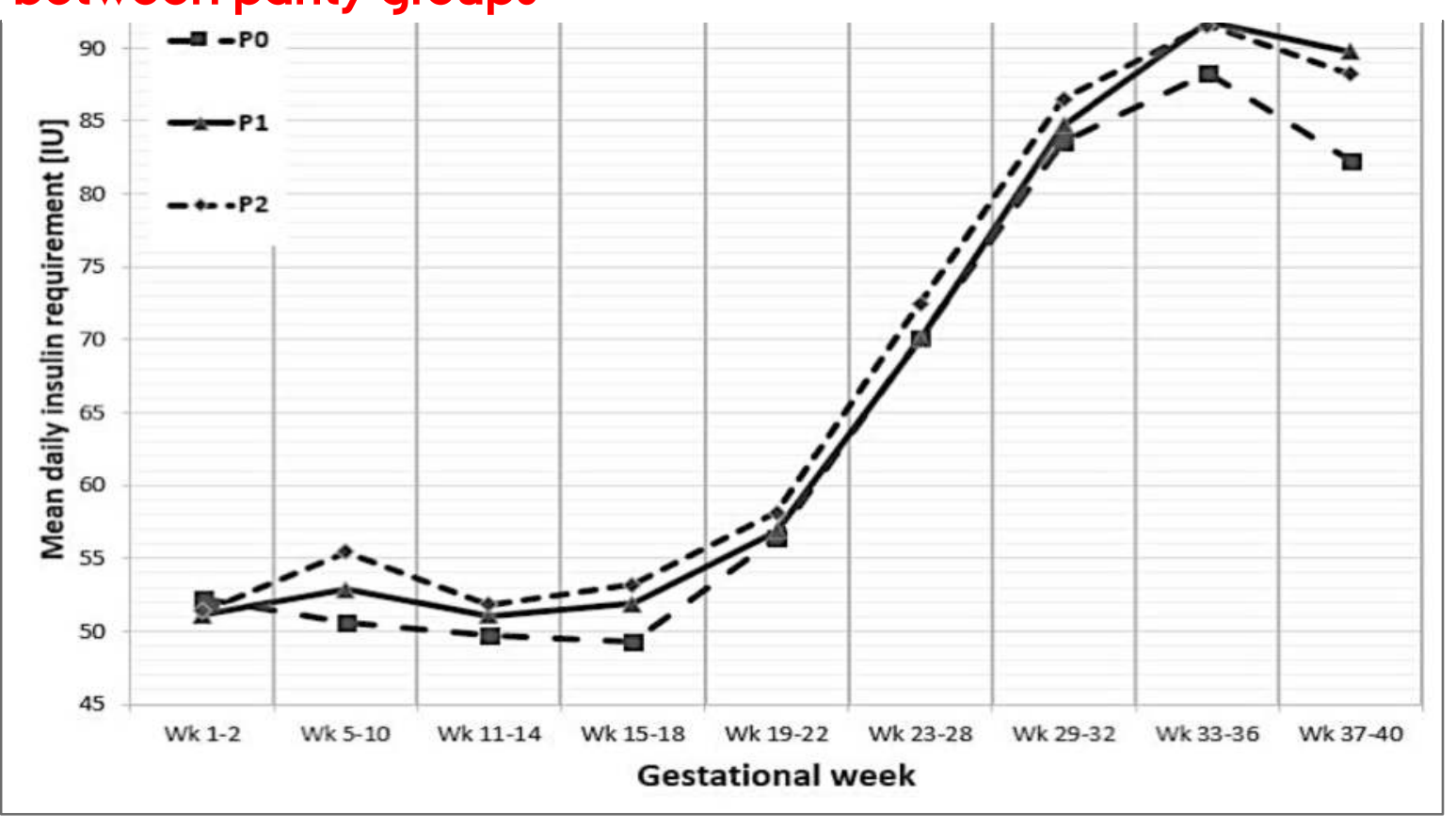

Table 2: Comparison of insulin requirement between parity groups

Unadjusted
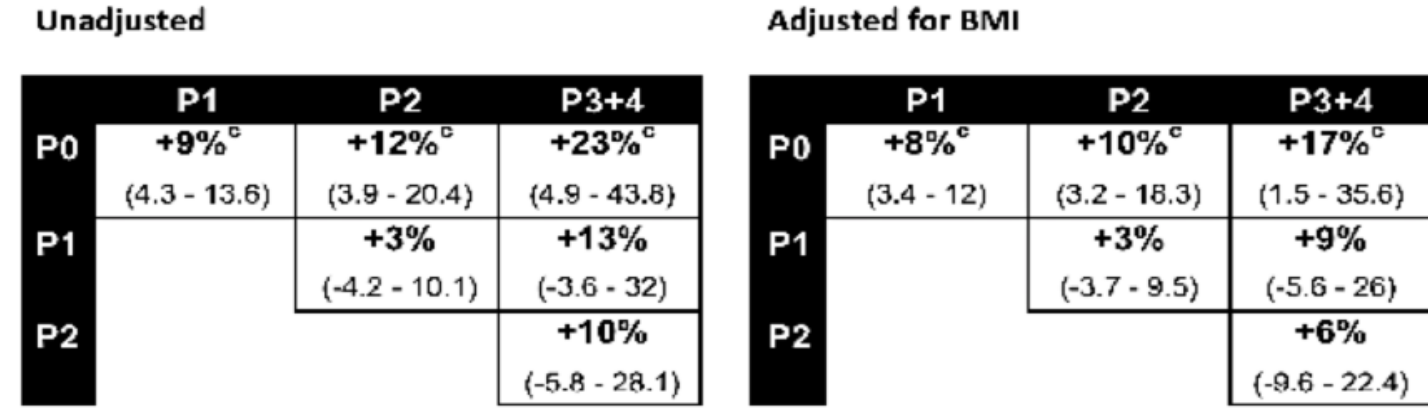

Adjusted for BMI and Age

Adjusted for BMI, Age and HbA1c
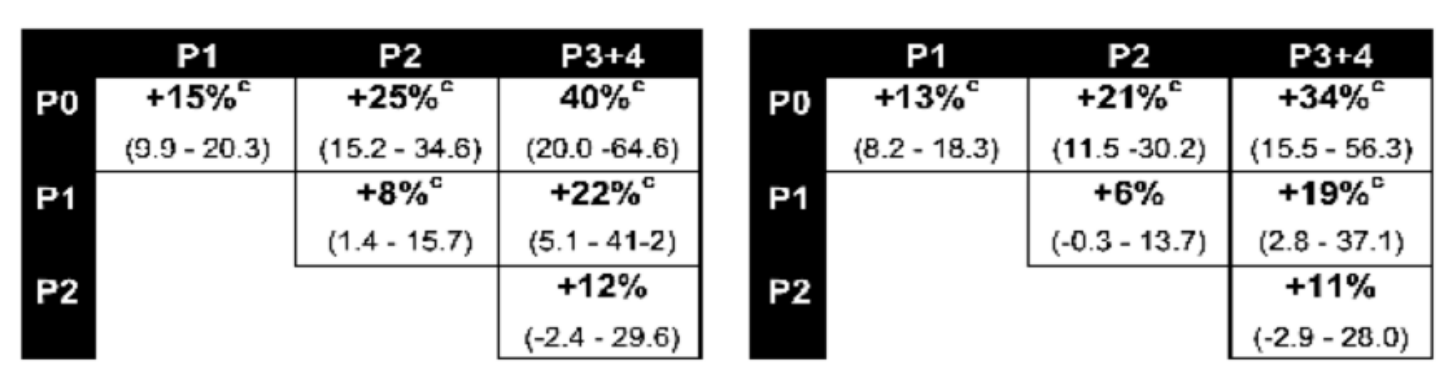

Adjusted for BMI, Age, HbA1c" and DD"

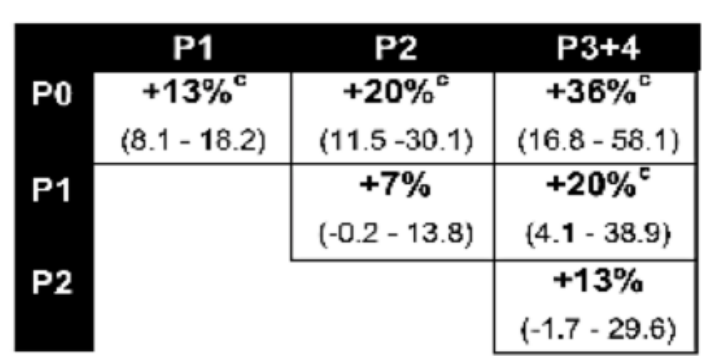

\section{CONCLUSION}

Our data show that parity per se increases insulin requirements during pregnancy between 9 and $36 \%$ in type 1 diabetes and confirm that insulin dosages exhibit a characteristic pattern with a modest early decrease and a pronounced late increase during pregnancy. This provides valuable information to achieve tight glycemic control throughout pregnancy.

Being the first report to show this, our findings may have straight clinical implications for pregnant type 1 diabetes patients. 